Abstract-Age underestimation of many shark species, such as the sandbar shark (Carcharhinus plumbeus), has been proven with age validation methods including bomb radiocarbon dating, oxytetracycline (OTC) injection, and tagrecapture data. Validation studies indicate that band-pair deposition in vertebral centra may not be directly related to time, especially in older individuals of a species. In this study, vertebrae from tagged, OTCinjected, and recaptured sandbar sharks were examined to determine if band-pair deposition past the OTC mark matched time at liberty. In 6 of 8 OTC-injected sharks at liberty for $>1$ year, band-pair count past the OTC mark underestimated time at liberty by $24-58 \%$. Additionally, growth rates derived from tag-recapture data were slower than those described by previously published vertebral band-pair growth curves but were similar to those predicted by previous bomb radiocarbon dating and OTC results from this study. Together, the results from these studies indicate that modeling tag-recapture data may be more accurate for age determination in elasmobranchs given that band-pair counts on vertebral centra do not coincide with age throughout life. Analyses indicate that sandbar sharks may be less productive than previously understood.

Manuscript submitted 13 August 2018. Manuscript accepted 20 December 2018. Fish. Bull. 117:50-58 (2019).

Online publication date: 8 February 2019. doi: 10.7755/FB.117.1.6

The views and opinions expressed or implied in this article are those of the author (or authors) and do not necessarily reflect the position of the National Marine Fisheries Service, NOAA.

\title{
Using oxytetracycline validation for confirmation of changes in vertebral band-pair deposition rates with ontogeny in sandbar sharks (Carcharhinus plumbeus) in the western North Atlantic Ocean
}

\author{
Lisa J. Natanson (contact author) ${ }^{1}$ \\ Bethany M. Deacy ${ }^{2}$ \\ Email address for contact author: lisa.natanson@noaa.gov \\ 1 Northeast Fisheries Science Center \\ National Marine Fisheries Service, NOAA \\ 28 Tarzwell Drive \\ Narragansett, Rhode Island 02882 \\ 2 Riverside Technologies, Inc. \\ for National Marine Fisheries Service, NOAA \\ 3500 Delwood Beach Road \\ Panama City, Florida 32408
}

Research has shown that the rate of vertebral band-pair deposition in elasmobranchs is variable and not necessarily related to time (Harry, 2018; Natanson et al., 2018). At least $30 \%$ of studies attempting to validate the periodicity of vertebral band-pair deposition in elasmobranchs in relation to age have shown that ages were underestimated (Harry, 2018). Results from the use of oxytetracycline (OTC) injection, tag-recapture data, and bomb radiocarbon dating for validation indicate that bandpair deposition in sharks can approximate time in certain life stages (e.g., Campana et al., 2002; Natanson et al., 2002; Francis et al., 2007; Andrews et al., 2011; Wells et al., 2013; Hamady et al., 2014; Passerotti et al., 2014; Natanson and Skomal, 2015; Kinney et al., 2016; Harry, 2018). A change in band-pair deposition rate often occurs at the approach of maturity, indicating that bandpair deposition rate changes with shifts in the growth rate associated with energetic demands required by a maturing fish. In some species, such as the Pacific angel (Squatina californica) and basking (Cetorhinus maximus) sharks, there is no apparent link to time at any life stage (Natanson and Cailliet, 1990; Natanson et al., 2008). Furthermore, examination of vertebral band-pair counts in relationship to vertebral and somatic growth in 7 elasmobranch species has revealed a relationship between body girth and band-pair deposition. This finding indicates that, although there may be a coincidental link to time in band-pair deposition, bandpair deposition is more likely related to vertebral structure (Natanson et al., 2018). The results of all of these studies reemphasize the importance of direct validation of all sizes of a species (Beamish and McFarlane, 1983).

The sandbar shark (Carcharhinus plumbeus) is a common coastal carcharhinid that is widely distributed in the world's oceans (Ebert et al., 2013). In the western North Atlantic Ocean, the sandbar shark is distributed from southern Massachusetts to Florida, into the Gulf of Mexico, and to southern Brazil (Castro, 2011). This shark has been the primary 
target species of the bottom longline fishery for coastal sharks since the 1980s (NMFS, 1993). In 2007, amendments to the Consolidated Atlantic Highly Migratory Species Fisheries Management Plan limited the take of the sandbar shark to a research fishery with the intent to collect life-history and catch data (NMFS, 2007). Since the implementation of this research fishery, collected vertebral samples have been used for age and growth analysis for the stock assessment of this species (SEDAR, 2011, 2017).

Discrepancies exist among the previously published age and growth studies on sandbar sharks, largely because of lack of validation of band-pair periodicity in the early vertebral studies (Casey et al., 1985; Casey and Natanson, 1992; Sminkey and Musick, 1995; Andrews et al., 2011; Hale and Baremore, 2013; Romine et al., 2013). Both growth curves generated in models from tag-recapture data and results from bomb radiocarbon analyses suggest slower growth and a longer lifespan than that estimated by using band-pair counts on vertebral centra (Casey and Natanson, 1992; Andrews et al., 2011). Additionally, results from the bomb radiocarbon technique indicate that band-pair counts approximated annual deposition only until 10-12 years of age (Andrews et al., 2011).

We report on a long-term field study undertaken by the National Marine Fisheries Service's Cooperative Shark Tagging Program to validate the band-pair periodicity of the sandbar shark in the western North Atlantic Ocean. Results from recaptured sandbar sharks that were tagged and injected with OTC between 1985 and 2017 are presented and compared with results from previous studies. We also updated the tag-recapture growth curve of sandbar sharks generated by Casey and Natanson (1992) to refine growth estimates.

\section{Materials and methods}

The Cooperative Shark Tagging Program tagged 39,405 and recaptured 1603 sandbar sharks between 1962 and 2017. Data recorded at tagging and recapture included size (fork length, total length, or weight), sex, location, and date; these data are referred to as tag-recapture data for the remainder of this paper. Sharks were tagged and recaptured by biologists, fisheries observers, and commercial and recreational fishermen in the United States. Sharks tagged for age validation studies were injected with a dose of OTC (25 mg per $1 \mathrm{~kg}$ of body weight), primarily by biologists on research vessels, and precisely measured before release. Only vertebrae from sharks with a reliably measured fork length (FL, from the tip of the snout to the fork in the tail, over the body) or total length (TL, from the tip of the snout to a point on the horizontal axis intersecting a perpendicular line extending downward from the tip of the upper caudal lobe to form a right angle, over the body; Kohler et al., 1996) at both tagging and recapture were used in this study. We determined the reliability of measurement data on the basis of prior knowledge of the individual measuring the shark or detailed questioning of those individuals as to the method used. Measurements were converted to over-the-body FL, when necessary, by using the following equation (Kohler et al., $1996 ; n=3734$; coefficient of determination $\left.\left[r^{2}\right]=0.9933\right)$ :

$$
F L=0.8175(T L)+2.5676 .
$$

\section{Processing of vertebrae}

For each shark, multiple vertebrae were removed from the area just posterior to the branchial chamber wherever possible; vertebrae were obtained closer to the head when sampling occurred onboard commercial vessels. We acknowledge that vertebral centra from different parts of the vertebral column in carcharhinids have been shown to have varying band-pair counts associated with vertebral size (Natanson et al., 2018). Preliminary data show that, for sandbar sharks in the size range used in this study, band-pair count will be consistent along the vertebral column, allowing us to use vertebra from differing parts of the body (senior author, unpubl. data). All vertebrae processed for bandpair counts were stored frozen or in $70 \%$ ethyl alcohol in the dark until processing. Individual vertebrae were sectioned laterally through the focus by using gross sectioning (Natanson et al., 2006).

\section{Validation with oxytetracycline marking}

The accuracy of vertebral band-pair counts for use as annual indicators of growth was determined by using individuals that were recaptured after they were injected with OTC, tagged, and released. Between 1985 and 2017, 7556 tagged sandbar sharks were injected with OTC, and data from 279 sharks (3.7\%) were returned by 2017 . Vertebrae obtained from 12 of these recaptured sandbar sharks were examined. Two pictures of each section, in the identical position, were taken by using 1) reflected white light for band-pair counts and 2) reflected long-wave UV light (366 $\mathrm{nm})$ with the exposure increased to $20 \mathrm{~s}$ to obtain images of the OTC mark. Images were taken with a Nikon DSR $12^{1}$ digital camera (Nikon Corp., Tokyo, Japan) attached to a Nikon SMZ1500 stereo microscope (Nikon Instruments, Inc., Melville, NY). Magnification varied with the size of the section, and a scale was included in each photo.

Band pairs (consisting of one opaque and one translucent band; Casey et al., 1985) were counted and marked independently by 2 experienced age readers using image editing software (Adobe Photoshop Elements 6, Adobe, Inc., San Jose, CA). Each band pair was marked on an individual layer in Adobe Photoshop by the readers following Natanson et al. (2018), and each layer was considered a count. Once the readers

\footnotetext{
${ }^{1}$ Mention of trade names or commercial companies is for identification purposes only and does not imply endorsement by the National Marine Fisheries Service, NOAA.
} 


\section{Table 1}

Tag-recapture data and vertebral band-pair counts for 12 recaptured sandbar sharks (Carcharhinus plumbeus) injected with oxytetracycline (OTC) and tagged between 1983 and 2009 in the western North Atlantic Ocean. The relationship between years at liberty (YAL) and counts of vertebral band pairs (BP) is included (BP-YAL). An asterisk $\left(^{*}\right)$ indicates an estimated length. The last 4 sharks were either at liberty for less than 1 year or had no visible OTC mark and were not included in analysis. $\mathrm{TFL}=$ fork length at tagging; $\mathrm{RFL}=$ fork length at recapture; VR=vertebral radius; $\mathrm{M}=$ mature; and $\mathrm{UNK}=\mathrm{unknown}$ sex.

\begin{tabular}{|c|c|c|c|c|c|c|c|c|c|c|c|c|}
\hline $\begin{array}{l}\text { Specimen } \\
\text { ID code }\end{array}$ & Sex & $\begin{array}{l}\text { TFL } \\
(\mathrm{cm})\end{array}$ & $\begin{array}{l}\text { RFL } \\
(\mathrm{cm})\end{array}$ & $\begin{array}{c}\text { Date } \\
\text { tagged }\end{array}$ & $\begin{array}{c}\text { Date } \\
\text { recaptured }\end{array}$ & YAL & $\begin{array}{l}\text { Growth } \\
(\mathrm{cm})\end{array}$ & $\begin{array}{c}\text { No. of } \\
\text { BPs past } \\
\text { OTC mark }\end{array}$ & $\begin{array}{c}\text { Total no. } \\
\text { of BPs }\end{array}$ & BP-YAL & Maturity & $\begin{array}{c}\text { Underestimation } \\
\text { between BP } \\
\text { and YAL }(\%)\end{array}$ \\
\hline CM1025 & $\mathrm{F}$ & 119 & 159 & $5 / 16 / 2001$ & 6/28/2017 & 16.12 & 40 & 7.0 & 14.0 & -9.12 & M & 56.58 \\
\hline CM1029 & $\mathrm{F}$ & 136 & 156 & $11 / 14 / 2000$ & $5 / 26 / 2010$ & 9.53 & 20 & 4.0 & 14.0 & -5.53 & UNK & 58.03 \\
\hline CM1024 & $\mathrm{M}$ & 129 & 154 & $5 / 2 / 2009$ & $5 / 29 / 2017$ & 8.10 & 25 & 4.0 & 13.0 & -4.1 & M & 50.62 \\
\hline CM945 & $\mathrm{F}$ & 68 & 150 & $10 / 25 / 1996$ & 8/8/2002 & 11.77 & 82 & 9.0 & 11.0 & -2.77 & UNK & 23.53 \\
\hline CM1026 & $\mathrm{F}$ & 114 & 132 & 8/6/1986 & 7/29/1993 & 6.98 & 18 & 5.0 & 13.0 & -1.98 & UNK & 28.37 \\
\hline CM867 & $\mathrm{M}$ & 115 & 134 & $5 / 19 / 1989$ & 2/22/1993 & 3.76 & 19 & 2.5 & 10.0 & -1.26 & UNK & 33.51 \\
\hline CM1031 & $\mathrm{M}$ & 56 & 156 & 9/21/1998 & 6/4/2014 & 15.70 & 100 & 15.5 & 16.0 & -0.20 & M & \\
\hline CM1027 & $\mathrm{F}$ & 85 & 147 & 8/3/1996 & $7 / 27 / 2006$ & 9.98 & 62 & 10.0 & 13.0 & 0.02 & UNK & \\
\hline CM751 & $\mathrm{M}$ & 56 & 59 & $7 / 31 / 1983$ & 9/7/1983 & 0.10 & 3 & $<1$ & & & & \\
\hline CM932 & $\mathrm{F}$ & 150 & 153 & $11 / 14 / 2000$ & $3 / 1 / 2001$ & 0.29 & 3 & $<1$ & & & & \\
\hline CM1028 & $\mathrm{F}$ & 160 & $165^{*}$ & $4 / 22 / 2009$ & $8 / 25 / 2010$ & 1.34 & 5 & No OTC & & & & \\
\hline CM1030 & $\mathrm{M}$ & $130^{*}$ & 153 & $5 / 4 / 2009$ & 6/6/2011 & 2.01 & 23 & No OTC & & & & \\
\hline
\end{tabular}

agreed on a final count, a layer with the OTC mark was superimposed on the consensus layer. The transparency of the OTC layer was decreased until the marks on the consensus layer were visible.

\section{Growth analysis with tag-recapture data}

Data from only those sharks at liberty for $>1$ year and with a reliably measured body length at both tagging and recapture were used in growth curve analysis $(n=149)$. Parameters for the von Bertalanffy growth function from the tag-recapture data were generated by using both the Gulland and Holt (1959) and GROTAG (Francis, 1988) models in R, vers. 3.5.1 (R Core Team, 2018).

The Francis (1988) method (GROTAG) uses maximum likelihood techniques to estimate growth parameters and variability from tagging data. A coefficient of variation of growth variability $(v)$, the mean and standard deviation of measurement errors $(s=$ standard deviation of measurement error), and outlier contamination $(p)$ are estimated as well as growth rates at 2 user-selected lengths ( $\alpha$ and $\beta$ ). The reference lengths, $\alpha$ and $\beta$, were chosen to lie within the range of tagged individuals. The form of the von Bertalanffy equation becomes

$$
\Delta L=\left[\frac{\beta g_{\alpha}-\alpha g_{\beta}}{g_{\alpha}-g_{\beta}}\right]\left[1-\left(1+\frac{g_{\alpha}-g_{\beta}}{\alpha-\beta}\right)^{\Delta \mathrm{T}}\right],
$$

where $L_{1}=$ the length at tagging;

$\Delta L=$ the increment in length;

$\Delta T=$ the increment in time; $g_{\alpha}=$ the mean annual growth rate at arbitrary length $\alpha$; and

$g_{\beta}=$ the mean annual growth rate at the arbitrary length $\beta$.

Mean annual growth rates for the GROTAG model were estimated at 60 and $160 \mathrm{~cm} \mathrm{FL}$ to represent the size ranges of the sandbar shark. The simplest model, a linear fit with minimal parameters ( $\alpha$ and $s$ ), was used initially, with additional parameters added to successively increase model complexity. Significant improvement in the model results was achieved by using log-likelihood ratio tests (Francis, 1988). The model searches for the set of parameters that maximize the $\log$-likelihood ratio $(\lambda)$. The introduction of additional parameters must increase $\lambda$ by 1.92 to be significant $(P<0.05)$ (Francis, 1988).

The value of the theoretical age at which a fish would have zero length $\left(t_{0}\right)$ cannot be estimated from tagging data alone; rather, it requires an estimate of absolute size at age, such as size at birth. We calculated $t_{0}$ with the von Bertalanffy growth function (von Bertalanffy, 1939) by using the following equation:

$$
t_{0}=t+(1 / k)\left[\ln \left\{\left(L_{\infty}-L_{\mathrm{t}}\right) / L_{\infty}\right\}\right]
$$

where $L_{\mathrm{t}}=$ known length at age (size at birth);

$L_{\infty}=$ mean asymptotic fork length;

$t=$ age; and

$k=$ a growth constant (per year).

The $t_{0}$ values were calculated on the basis of an average size at birth of $47.7 \mathrm{~cm}$ FL (Casey et al., 1985) with $t=0$. Values for $L_{\infty}$ and $k$ were calculated in the tag-recapture models. 


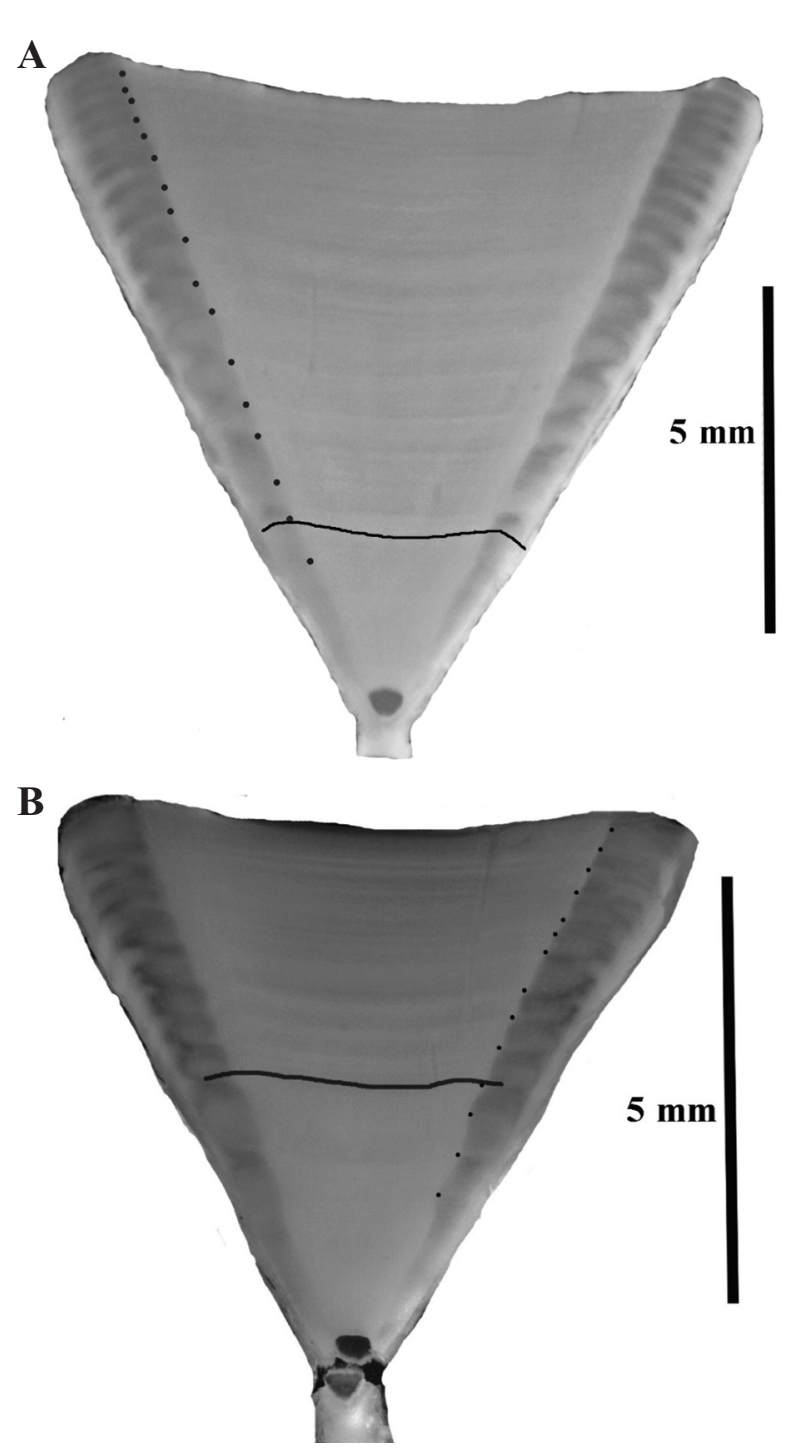

Figure 1

Images of sections of vertebral centra from 2 sandbar sharks (Carcharhinus plumbeus) injected with oxytetracycline (OTC) and tagged in the western North Atlantic Ocean in 1998 and 1996, respectively: (A) CM1031, which measured $156 \mathrm{~cm}$ in fork length (FL) at recapture in 2014, and (B) CM1027, which was $147 \mathrm{~cm}$ FL at recapture in 2006. The black line indicates the location of the OTC mark, and the black dots indicate the band pairs visible past the OTC mark.

To directly compare validated age estimates at recapture for OTC-injected sharks to the age estimates at size obtained from the tag-recapture models, age at tagging had to be assigned to each individual. Bandpair counts proximal to the OTC mark were used to assign age at tagging. Because counts of band pairs in sandbar sharks have been validated as annual up to 10-12 years (Branstetter, 1987; Andrews et al., 2011), if the band-pair count proximal to the OTC mark was less than 12, an age at tagging could be assigned. Age at recapture then was estimated by adding time at liberty after tagging to count of band pairs proximal to the OTC mark. For example, a shark (CM1029) had 10 band pairs before the OTC mark and was at liberty for 9.5 years, resulting in age estimates of 10.0 years at tagging and 19.5 years at recapture. Then, estimates of age at recapture, along with the sizes at recapture, were compared with growth curves from the GROTAG model from this study and vertebral and tag-recapture models from previous studies (Casey et al., 1985; Casey and Natanson, 1992). Numbers of band pairs past the OTC mark were plotted against time at liberty along with a 1:1 line to determine whether band-pair counts were annual after the OTC mark.

\section{Results}

\section{Validation with oxytetracycline marking}

Times at liberty for 12 recaptured sharks that were injected with OTC ranged from 0.1 to 16.1 years. Vertebrae from 10 of these specimens had a distinct OTC mark; 2 had no visible mark. Eight of these 10 recaptured sharks were at liberty for $>1$ year $(3.8-16.1$ years) and were used for validation analyses (Table 1). The remaining 2 specimens were at liberty for 0.1 and 0.3 years $(38-107 \mathrm{~d})$, indicating that OTC was incorporated into the vertebra shortly after injection but growth distal to the mark was minimal. The size of specimens from which vertebrae were used ranged from 56 to $136 \mathrm{~cm} \mathrm{FL} \mathrm{at} \mathrm{tagging} \mathrm{(Table} \mathrm{1).} \mathrm{One} \mathrm{shark}$ (CM1031) was tagged as a young of the year; therefore, it also was considered to have a known age at tagging $(56 \mathrm{~cm} \mathrm{FL})$. Assigning a date of birth of 1 May to this sandbar shark (Baremore and Hale, 2012) meant it was $\sim 4$ months old at tagging, and adding those 4 months to this shark's 15.7 years at liberty resulted in an estimate of 16.1 years for its age at recapture. Data from another known young-of-the-year shark (CM751) indicate that OTC was incorporated within a month; therefore, the OTC mark in this animal was very close to the first clear band pair, possibly confirming Branstetter's (1987) estimate that the first band pair is deposited at 6 months of age (Fig. 1).

Band-pair count past the OTC mark underestimated time at liberty from $23.5 \%$ to $58.0 \%$ in 6 of the 8 recaptured sandbar sharks and validated annual deposition in the remaining 2 individuals at liberty for $>1$ year (Table 1, Fig. 2). Underestimation of age from the use of band-pair count past the OTC mark varied between 1.3 and 9.1 years. Although data are limited, age underestimation from the use of band-pair counts does not appear related to sex because band-pair counts underestimated ages for individuals of both sexes.

Sandbar sharks that were smaller at tagging $(<100$ cm FL) showed less deviation between band-pair count and time at liberty. Annual band-pair deposition past 


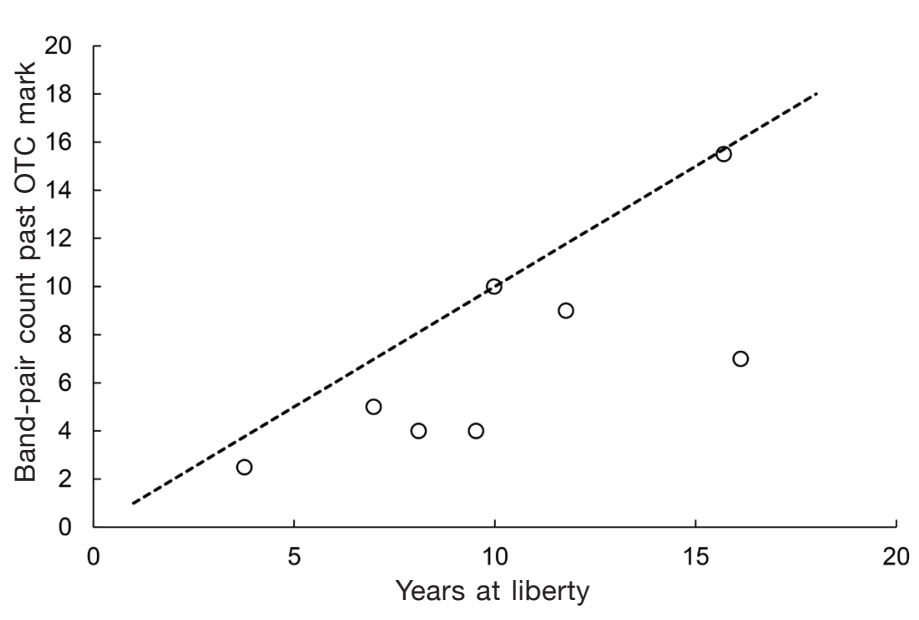

Figure 2

Relationship of time at liberty to count of vertebral band pairs past the mark from oxytetracycline (OTC) injection for the 8 growth analysis for this study. These sharks were tagged from 1986 through 2009 in the western North Atlantic Ocean. The dashed line indicates the 1:1 relationship. recaptured sandbar sharks (Carcharhinus plumbeus) used in

and August ( $n=22$ each) and the lowest numbers of sharks taken in September, November, and December ( $n=5,4,2$, respectively). The results of the log-likelihood ratio tests using the GROTAG model (Francis, 1988) indicate that the more complex nonlinear model with all 6 of the parameters included was the best fit for these data (see estimates for Model 4 in Table 2). The mean annual growth rates were calculated at $60 \mathrm{~cm} \mathrm{FL}(10.65 \mathrm{~cm} /$ year $)$ and $160 \mathrm{~cm} \mathrm{FL} \mathrm{(1.67} \mathrm{cm/year;} \mathrm{Table} \mathrm{2).} \mathrm{The} \mathrm{fits}$ failed for Models 1 and 5 (Table 2). We compared results for parameters of the von Bertalanffy growth function: estimates of $L_{\infty}$ were higher and estimates of $k$ were lower from the Gulland and Holt (1959) model than from the GROTAG model (Francis, 1988). In addition, although the growth curves from these 2 models look similar up to approximately age 20, the Gulland and Holt (1965) model produces a curve with slightly higher length-at-age estimates past this age (Table 3 , Fig. 2). The ages validated with bomb radiocarbon dating for sharks in Andrews et al. (2011) and the known ages for OTC-injected sharks in this study follow the updated growth curves based on current tag-recapture data, rather than the growth curve based on previously published vertebral band-pair count data (Fig. 3).

mark was seen in 2 of the 3 smallest shark (CM1031 and CM1027), and the age of the third shark (CM945) was underestimated by $23.5 \%$ (Table 1). Conversely, the degree of underestimation was greater for sharks that were larger $(\geq 129 \mathrm{~cm} F L)$ at tagging (CM1025, CM1029, and CM1024). On the basis of bomb radiocarbon validation (Andrews 2011), we would expect annual periodicity to be approximately 12 years; the amount of time at liberty past 12 years would determine the amount of age underestimation. Therefore, a lower amount of age underestimation is expected because of the limited time of growth beyond 12 years in 2 sharks (CM1031 and CM1027), which were small at tagging compared with the sharks at liberty for the same period of time but tagged at a larger size (CM1025 and CM 1029). For example, for 1 of these small sharks (CM1027), 13 total band pairs were counted and validated as annual, but for 2 of the large sharks (CM1025 and CM1029) counts of 14 band pairs underestimated times at liberty by 9.1 and 5.5 years, respectively (Table 1 ).

\section{Growth analysis with tag-recapture data}

Tag-recapture data for 149 sandbar sharks were used in the Gulland and Holt (1959) and GROTAG (Francis, 1988) models for growth analysis. Time at liberty ranged from 1.0 to 25.0 years, and size at tagging ranged from 48.0 to $172.8 \mathrm{~cm} \mathrm{FL} \mathrm{(Suppl.} \mathrm{Table).} \mathrm{Tag-}$ ging was conducted in all months except December, with most tags deployed from May through August $(n=101)$. These sharks were recaptured in all months of the year, with the most sharks taken in June, July,

\section{Discussion}

In view of current knowledge that using vertebral centra age estimates in larger sharks is not correct (Harry, 2018; Natanson et al., 2018), it is clear that growth models when used with extensive tag-recapture data can provide more accurate age estimates. As shown in this study, sharks with validated ages, such as those from OTC marking in this study and bomb radiocarbon dating (Andrews et al., 2011), are more closely aligned with tag-recapture-based growth curves than growth curves derived from vertebral band-pair counts. Sharks with validated ages started to deviate from the growth curves based on vertebral band-pair counts and followed the growth curves based on tag-recapture data by 12-16 years, indicating that, by this range of ages, variation among individual sharks in rate of band-pair deposition was possibly related to growth rate during the maturation process (Fig. 3).

Determination of age in elasmobranchs from bandpair counts on vertebral centra has relied on the caveat that each band pair represents a year. However, in $75 \%$ of the vertebrae from specimens in this study, it has been shown that the band pairs are not annual throughout life; band-pair counts underestimate age in these specimens. The 2 sharks that exhibited annual band-pair deposition were both tagged at smaller sizes; on the sample from the smallest individual, the OTC mark was seen just past the birth band, but, on the 


\begin{tabular}{|c|c|c|c|c|c|c|}
\hline \multicolumn{7}{|c|}{ Table 2} \\
\hline \multicolumn{7}{|c|}{$\begin{array}{l}\text { Log-likelihood ratio values and estimates of von Bertalanffy growth function param- } \\
\text { eters for } 5 \text { versions of the GROTAG model (Francis, 1988) fitted to tagging data for } 149 \\
\text { sandbar sharks tagged between } 1965 \text { and } 2013 \text { in the western North Atlantic Ocean. } \\
\text { The mean annual growth rates were calculated at } 60 \mathrm{~cm} \text { FL and } 160 \mathrm{~cm} \text { FL, and } \\
\text { standard errors of the mean (SEs) are given. For each version of the model, a param- } \\
\text { eter was added. For a significant }(P<0.05) \text { improvement in fit, the introduction of one } \\
\text { extra parameter must increase the log-likelihood function }(\lambda) \text { by at least } 1.92 \text { (Fran- } \\
\text { cis, } 1988 \text { ). An asterisk }(*) \text { indicates fixed parameters. There are no data for models } 1 \\
\text { and } 5 \text { because of failed fits. AIC=Akaike information criterion; } s=\text { standard deviation } \\
\text { of measurement error; } m=\text { mean measurement error; } p=\text { a contamination probability. }\end{array}$} \\
\hline \multirow[b]{2}{*}{ Parameter } & \multirow[b]{2}{*}{ Symbol (unit) } & \multicolumn{5}{|c|}{ Model } \\
\hline & & 1 & 2 & 3 & 4 & 5 \\
\hline \multirow[t]{2}{*}{ Log likelihood } & 1 & & -550.3 & -541.1 & -539.1 & \\
\hline & AIC & & 1108.6 & 1092.2 & 1094.1 & \\
\hline \multirow[t]{3}{*}{ Mean growth rates } & $\begin{array}{c}\mathrm{G}_{60}(\mathrm{~cm} / \mathrm{y}) \\
\mathrm{SE}\end{array}$ & & 14.17 & 11.00 & 10.65 & \\
\hline & $\mathrm{G}_{160}(\mathrm{~cm} / \mathrm{y})$ & & 1.67 & 1.67 & 1.67 & \\
\hline & $\mathrm{SE}$ & & & & 0.48 & \\
\hline Growth variability & $v$ & $0^{*}$ & 0.098 & 0.166 & 0.149 & $0 *$ \\
\hline \multirow{2}{*}{ Measurement error } & $s(\mathrm{~cm})$ & & 9.260 & 8.167 & 7.647 & \\
\hline & $m(\mathrm{~cm})$ & $0^{*}$ & $0^{*}$ & 5.164 & 5.288 & $0^{*}$ \\
\hline Outliers & $p$ & $0^{*}$ & $0^{*}$ & $0 *$ & 0.022 & \\
\hline
\end{tabular}

larger individual, the OTC mark was at the third band pair past the birth band (Fig. 1). The smaller of these 2 sharks (CM1031) was at liberty for 15.7 years, recaptured at a size of $156 \mathrm{~cm} \mathrm{FL}$, and classified as mature. The larger shark (CM1027), however, was recaptured at a size of $147 \mathrm{~cm}$ FL after 10 years at liberty and, on the basis of size, likely immature (estimated size at $50 \%$ maturity was 154.9 and $151.6 \mathrm{~cm} \mathrm{FL}$ for females and males, respectively; Baremore and Hale, 2012). These 2 sharks had total band-pair counts of 16 and 13, which are just over the number of band pairs at which Andrews et al. (2011) detected a shift from annual to non-annual band-pair deposition (10-12 years).

Size at both tagging and recapture appears to influence the amount of age underestimation in our OTC specimens. The percentage of time underestimated by band-pair counts $(23.5-58.0 \%)$ increased in relation to size at recapture and secondarily decreased with size at tagging, findings that are consistent with the conclusion that larger sharks (approaching maturity) have slower growth and deposit fewer band pairs than smaller sharks (young of the year and juveniles). For example, 2 sharks (CM1027 and CM1029) at liberty for approximately the same time but tagged at different sizes and, therefore, at different ages, had different outcomes regarding degree of age underestimation. In examined vertebral sections of the smaller of these 2 sharks (CM1027), 3 band pairs were visible before the OTC mark and deposition of band pairs before and after the OTC mark was annual. This individual's total age at recapture was 13.0 years, close to the age up to which band-pair deposition has been validated as annual for the sandbar shark (12 years; Andrews et al., 2011). In contrast, the other shark (CM1029) was tagged at a larger size and at an estimated age of 10.0 years, based on band-pair count before the OTC mark. The estimated total age for this shark was 19.5 years at recapture (10 band pairs +9.5 years at liberty), past the validated ages for annual deposition (10-12 years). Band-pair deposition in this individual had slowed; therefore, its age was underestimated.

Casey et al. (1985) aged the sandbar shark using vertebral band-pair counts and tag-recapture data. Their data indicated slower growth rates from using tag-recapture data than from counting vertebral band pairs, leading them to suggest that ages based on vertebral band-pair counts underestimate true age. These findings were reinforced by the results of Casey and Natanson (1992) and Andrews et al. (2011), who used tag-recapture data and bomb radiocarbon dating, respectively. At the time of these earlier studies, the use of vertebral data was considered more robust than other methods, and age estimations based on vertebral band-pair counts were generally accepted over results from other methods of age determination. In particular, the older ages at maturity and longevity estimated by using models with tag-recapture data were not considered reliable partly as a result of the low $L_{\infty}$ (often estimated by using this method because of a lack of large sharks reliably measured at tagging and recapture), which is highly linked to the $k$ value (von Bertalanffy, 1938). 


\section{Table 3}

The von Bertalanffy growth function parameters calculated by using tag-recapture data in models for sandbar sharks (Carcharhinus plumbeus) tagged and recaptured in the western North Atlantic Ocean: mean asymptotic fork length $\left(L_{\infty}\right)$, growth constant $(k)$, and theoretical age at a length of zero $\left(t_{0}\right)$.

\begin{tabular}{llccrr}
\hline Study & \multicolumn{1}{c}{ Model } & $L_{\infty}$ & $k$ & $t_{0}$ & $n$ \\
\hline This study & Gulland and Holt (1959) & 188.4 & 0.079 & -3.678 & 149 \\
This study & GROTAG (Francis, 1988) & 178.6 & 0.094 & -3.300 & 149 \\
Casey and Natanson (1992) & Fabens (1965) & 186.0 & 0.046 & -6.450 & 33
\end{tabular}

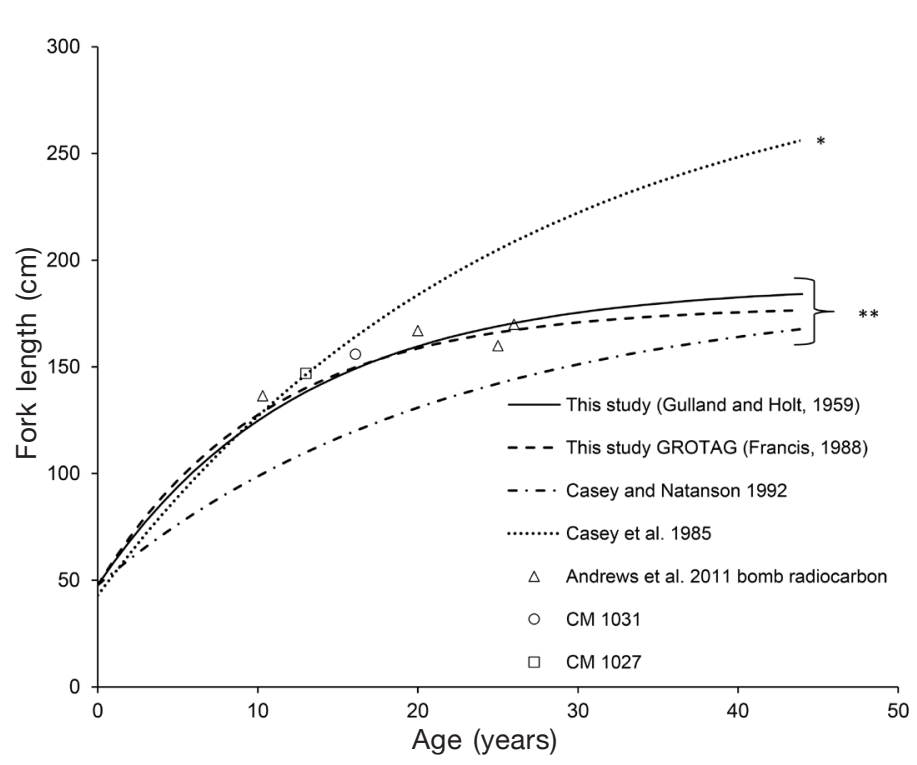

Figure 3

The von Bertalanffy growth curves generated in this study compared with previously published curves for the sandbar shark (Carcharhinus plumbeus). Estimated ages at recapture of oxytetracycline-injected sharks are included. The open triangles indicate ages validated with bomb radiocarbon dating for 4 specimens from Andrews et al. (2011). The open square and circle indicate the known ages used in this study for sandbar sharks tagged in 1996 (CM1027) and 1998 (CM 1031) in the western North Atlantic Ocean. The single asterisk (*) indicates a growth curve based on vertebral band-pair counts, and the double asterisks $(* *)$ indicate growth curves based on the use of tag-recapture data.

Modeling of tag-recapture data is provided as an alternate method of age determination. The growth curves derived from modeling tag-recapture data are verified by the close relationship of the estimated ages of OTC-marked individuals to the ages estimated for similarly sized fish by the tag-recapture growth curves. Both of the tag-recapture-derived models in this study output similar growth estimates to age 20 and predict higher $k$ values than growth estimates derived by Casey and Natanson (1992), but tag-recapture models from both studies underestimate $L_{\infty}$ (maximum observed size: $251 \mathrm{~cm} \mathrm{FL;} \mathrm{NMFS}^{2}$ ). We applied the size at $50 \%$ maturity calculated by Baremore and Hale (2012), 154.9 and $151.6 \mathrm{~cm} \mathrm{FL}$ for females and males, respectively, to the parameters we calculated by using the GROTAG (Francis, 1988) and Gulland and Holt (1959) models: results indicate that female and male sandbar sharks reach $50 \%$ maturity at an age of approximately 18 and 17 years, respectively. These estimates of age at $50 \%$ maturity are higher than those predicted by counting vertebral band pairs (12 and 13 years for females and males, respectively; Casey et al., 1985) and lower than that predicted by using the previous tag-recapture data (nearly 30 years; Casey and Natanson, 1992).

Our findings corroborate those of other studies on sandbar sharks (Casey et al., 1985; Casey and Natanson, 1992; Andrews et al., 2011) as well as on a multitude of other shark and ray species (Harry, 2018) and support the use of modeling with tag-recapture data as an alternative method of age determination. These results reinforce the notion that band-pair deposition may misrepresent the age of individuals, possibly affecting management of the sandbar shark because underestimation of age leads to underestimation of reproductive potential and overestimation of yield.

\section{Acknowledgments}

We would like to thank G. Skomal, H. Pratt, and J. Casey for starting the OTC program. N. Kohler was instrumental in safe handling of sharks during OTC injections. We also thank J. Carlson and the observer program staff of the Panama City Lab, National Marine Fisheries Service, for processing and sending samples. Samples could not have been ob-

2 NMFS (National Marine Fisheries Service). 2018. Unpubl. data. Panama City Laboratory, Southeast Fish. Sci. Cent., Natl. Mar. Fish. Serv., NOAA. 3500 Delwood Beach Rd., Panama City, FL 32408. 
tained without the help of commercial and recreational fishermen and fisheries observers. We also thank S. Wintner and W. Driggers for providing critical reviews that improved this paper.

\section{Literature cited}

Andrews, A. H., L. J. Natanson, L. A. Kerr, G. H. Burgess, G. M. Cailliet.

2011. Bomb radiocarbon and tag-recapture dating of sandbar shark (Carcharhinus plumbeus). Fish. Bull. 109:454-465.

Baremore, I. E., and L. F. Hale.

2012. Reproduction of the sandbar shark in the western North Atlantic Ocean and Gulf of Mexico. Mar. Coast. Fish. 4:560-572. Crossref

Beamish, R. J., and G. A. McFarlane.

1983. The forgotten requirement for age validation in fisheries biology. Trans. Am. Fish. Soc. 112:735-743. Crossref

Branstetter, S.

1987. Age and growth validation of newborn sharks held in laboratory aquaria, with comments on the life history of the Atlantic sharpnose shark, Rhizoprionodon terraenovae. Copiea 1987:291-300.

Campana, S. E., L. J. Natanson, and S. Myklevoll.

2002. Bomb dating and age determination of large pelagic sharks. Can. J. Fish. Aquat. Sci. 59:450-455. Crossref

Casey, J. G., and L. J. Natanson.

1992. Revised estimates of age and growth of the sandbar shark (Carcharhinus plumbeus) from the western North Atlantic. Can. J. Fish. Aquat. Sci. 49:1474-1477. Crossref

Casey, J. G., H. L. Pratt Jr., and C. E. Stillwell.

1985. Age and growth of the sandbar shark (Carcharhinus plumbeus) from the western North Atlantic. Can. J. Fish. Aquat. Sci. 42:963-975. Crossref

Castro, J. I.

2011. The sharks of North America, 640 p. Oxford Univ. Press, Inc., New York, NY.

Ebert, D. A., S. Fowler, and L. Compagno.

2013. Sharks of the world: a fully illustrated guide, $528 \mathrm{p}$. Wild Nature Press, Plymouth, UK.

Fabens, A. J.

1965. Properties and fitting of the von Bertalanffy growth curve. Growth 29:265-289.

Francis, M. P., S. E. Campana, and C. M. Jones.

2007. Age under-estimation in New Zealand porbeagle sharks (Lamna nasus): is there an upper limit to ages that can be determined from shark vertebrae? Mar. Freshw. Res. 58:10-23. Crossref

Francis, R. I. C. C.

1988. Maximum likelihood estimation of growth and growth variability from tagging data. N. Z. J. Mar. Freshw. Res. 22:43-51.

Gulland, J. A., and S. J. Holt.

1959. Estimation of growth parameters for data at unequal time intervals. ICES J. Mar. Sci. 25:47-49. Crossref

Hale, L. F., and I. E. Baremore.

2013. Age and growth of the sandbar shark (Carcharhinus plumbeus) from the northern Gulf of Mexico and the western North Atlantic Ocean. Gulf Mex. Sci. 31:28-39. Crossref
Hamady, L. L., L. J. Natanson, G. B. Skomal, and S. R. Thorrold.

2014. Vertebral bomb radiocarbon suggests extreme longevity in white sharks. PLoS ONE 9(1):e84006. Crossref

Harry, A. V.

2018. Evidence for systemic age underestimation in shark and ray ageing studies. Fish Fish. 19:185-200. Crossref

Harry, A. V., A. J. Tobin, and C. A. Simpfendorfer.

2013. Age, growth and reproductive biology of the spottail shark, Carcharhinus sorrah, and the Australian blacktip shark, C. tilstoni, from the Great Barrier Reef World Heritage Area, north-eastern Australia. Mar. Freshw. Res. 64:277-293. Crossref

Kinney, M. J., R. J. D. Wells, and S. Kohin.

2016. Oxytetracycline age validation of an adult shortfin mako shark Isurus oxyrinchus after 6 years at liberty. J. Fish Biol. 89:1828-1833. Crossref

Kohler, N. E., J. G. Casey, and P. A. Turner.

1996. Length-weight relationships for 13 species of sharks from the western North Atlantic. Fish. Bull. 93:412418.

Natanson, L. J., and G. M. Cailliet.

1990. Vertebral growth zone deposition in Pacific angel sharks. Copeia 1990:1133-1145.

Natanson, L. J., and G. B. Skomal.

2015. Age and growth of the white shark, Carcharodon carcharias, in the western North Atlantic Ocean. Mar. Freshw. Res. 66:387-398. Crossref

Natanson, L. J., J. J. Mello, and S. E. Campana.

2002. Validated age and growth of the porbeagle shark (Lamna nasus) in the western North Atlantic Ocean. Fish. Bull. 100:266-278.

Natanson, L. J., N. E. Kohler, D. Ardizzone, G. M. Cailliet, S. P. Wintner, and H. F. Mollet.

2006. Validated age and growth estimates for the shortfin mako, Isurus oxyrinchus, in the North Atlantic Ocean. Environ. Biol. Fish. 77:367-383. Crossref

Natanson, L. J., S. P. Wintner, F. Johansson, A. Piercy, P. Campbell, A. De Maddalena, S. J. B. Gulak, B. Human, F. C. Fulgosi, D. A. Ebert, et al.

2008. Ontogenetic vertebral growth patterns in the basking shark, Cetorhinus maximus. Mar. Ecol. Prog. Ser. 361:267-278. Crossref

Natanson, L. J., B. J. Gervelis, M. V. Winton, L. L. Hamady, S. J. B. Gulak, and J. K. Carlson.

2014. Validated growth estimates for Carcharhinus obscurus in the northwestern Atlantic Ocean, with pre- and post management growth comparisons. Environ. Biol. Fish. 97:881-896. Crossref

Natanson, L. J., G. B. Skomal, S. L. Hoffmann, M. E. Porter, K. J. Goldman, and D. Serra.

2018. Age and growth of sharks: do vertebral band pairs record age? Mar. Freshw. Res. 69:1440-1452. Crossref

NMFS (National Marine Fisheries Service).

1993. Fishery management plan for sharks of the Atlantic Ocean, 167 p. NOAA, Natl. Mar. Fish. Serv., Southeast Reg. Off., Silver Springs, MD.

2007. Final amendment 2 to the consolidated Atlantic highly migratory species fishery management plan, 726 p. NOAA, Natl. Mar. Fish. Serv., Off. Sustainable Fish., Highly Migratory Species Manage. Div., Silver Spring, MD.

Passerotti, M. S., A. H. Andrews, J. K. Carlson, S. P. Wintner, K. J. Goldman, and L. J. Natanson.

2014. Maximum age and missing time in the vertebrae of sand tiger shark (Carcharias taurus): validated lifespan 
from bomb radiocarbon dating in the western North Atlantic and southwestern Indian Oceans. Mar. Freshw. Res. 65:674-687. Crossref

$\mathrm{R}$ Core Team.

2018. R: a language and environment for statistical computing. R Foundation for Statistical Computing, Vienna, Austria. [Available from website, accessed July 2018.]

Romine, J. G., J. A. Musick, and R. A. Johnson.

2013. Compensatory growth of the sandbar shark in the western North Atlantic including the Gulf of Mexico. Mar. Coast. Fish. 5:189-199. Crossref

SEDAR (Southeast Data Assessment and Review).

2011. SEDAR 21 stock assessment report: HMS sandbar shark, 435 p. SEDAR, North Charleston, SC. [Available from website.]
2017. SEDAR 54 stock assessment report: HMS sandbar shark, 176 p. SEDAR, North Charleston, SC. [Available from website.]

Sminkey, T. R., and J. A. Musick.

1995. Age and growth of the sandbar shark, Carcharhinus plumbeus, before and after population depletion. Copeia 1995:871-883.

von Bertalanffy, L.

1938. A quantitative theory of organic growth (inquiries on growth laws II). Hum. Biol. 10:181-213.

Wells, R. J. D., S. E. Smith, S. Kohin, E. Freund, N. Spear, and D. A. Ramon.

2013. Age validation of juvenile shortfin mako (Isurus oxyrinchus) tagged and marked with oxytetracycline off southern California. Fish. Bull. 111:147-160. Crossref 